\title{
PEMANFAATAN LIMBAH LATEKS KARET ALAM DENGAN PENGISI BUBUK PELEPAH PISANG SEBAGAI ADSORBEN MINYAK
}

\author{
Ismail Fahmi Hasibuan, Edward Tandy, Hamidah Harahap \\ Departemen Teknik Kimia, Fakultas Teknik, Universitas Sumatera Utara, \\ Jalan Almamater Kampus USU Medan 20155, Indonesia \\ Email: fahmi_i@ymail.com
}

\begin{abstract}
Abstrak
Pemanfaatan limbah lateks karet alam dengan pengisi bubuk pelepah pisang untuk dijadikan produk yang lebih berguna yaitu dijadikan adsorben minyak. Proses pembuatan adsorben diawali dengan mengeringkan pelepah pisang dan menghaluskannya hingga berukuran 100 mesh. Kemudian bubuk pelepah pisang dicampur dengan limbah lateks dengan variasi 10 dan $20 \%(b / b)$. Adapun analisis kemampuan daya adsorpsi adsorben dengan menggunakan persamaan isoterm Langmuir dan persamaan isoterm Freundlich. Penelitian dilakukan dengan proses batch dan mengguakan minyak pelumas sebagai adsorbatnya. Hasil yang diperoleh menunjukkan penambahan bubuk pelepah pisang sebagai pengisi adsorben limbah lateks meningkatkan kemampuan daya adsorpsi adsorbenminyak. Kesimpulan dari analisa karakteristik adsroben menunjukkan peningkatan jumlah bubuk pelepah pisang dapat meninggkatkan daya adsorpsi adsorben.
\end{abstract}

Kata Kunci: limbah lateks karet alam, bubuk pelepah pisang, adsorben minyak, kemampuan adsorpsi

\begin{abstract}
The use of waste of natural rubber latex with banana sheats powder filler to serve as a more useful product that is used as adsorbent of oil. The process begins with drying the adsorbent manufacture banana and polished up to 100 mesh size. Then the banana powder mixed with waste latex with variations of 10 and $20 \%(w / w)$. The analysis of the ability of the adsorbent adsorption isotherms using the Langmuir equation and Freundlich isotherm equation. Research carried out by the batch process and the use of lubricating oil as the adsorbate. The results obtained showed the addition of banana powder as filler waste adsorbent adsorption of latex increases the ability of the oil adsorbent. The conclusion of the analysis showed an increase in the number of characteristics adsroben banana powder can enhance the adsorption of adsorbent.
\end{abstract}

Keywords : natural rubber latex waste, banana sheaths powder, adsorbent oil, adsorption ability

\section{Pendahuluan}

Limbah seperti tumpahan minyak merupakan salah satu bentuk polusi yang dapat merusak lingkungan. Dampak dari tumpahan minyak ini dapat merusak ekosistem lingkungan terutama ekosistem di perairan. Tumpahan minyak di perairan dapat menghalangi masuknya oksigen terlarut ke dalam air.Beberapa teknik dapat digunakan untuk mengatasi tumpahan minyak diantaranya dengan menggunakan adsorben [1].

Adsorben merupakan zat padat yang dapat menyerap komponen tertentu dari suatu fase fluida. Kemampuan adsorben dalam menyerap komponen dipengaruhi oleh pori-pori yang terdapat pada suatu bahan. Pemisahan terjadi karena perbedaan bobot molekul atau karena perbedaan polaritas yang menyebabkan sebagian molekul melekat pada permukaan tersebut lebih erat daripada molekul lainnya. Adsorben yang digunakan secara komersial dapat dikelompokkan menjadi dua yaitu kelompok polar dan non polar [4].

Limbah lateks karet alam merupakan limbah lateks yang dihasilkan dari pengolahan industri karet alam. Limbah lateks karet alam terbentuk ketika lateks pada proses pra-vulkanisasi mengalami ovecured. Dampak dari limbah lateks karet alam ini dapat mengakibatkan bau yang tidak sedap dan kerusakan tanah yang disebabkan lamanya waktu degradasi limbah lateks di lingkungan. Cara untuk menanggulangi limbah lateks karet alam ini adalah memanfaatkannya sebagai adsorben minyak hal ini sejalan dengan penelitian yang dilakukan oleh Ismail Hanafi "A Novel and Reactive Oil Adsorben from Various Rubber Wastes" dimana limbah karet dapat dijadikan adsorben minyak yang mampu membersihkan tumpahan minyak di tanah dan dapat menjerap 5 kali beratnya di air [7]. Kemudian partikel karet ban bekas memiliki kemampuan adsorpsi sebesar $0,84 \mathrm{~g} \cdot \mathrm{g}^{-1}$ untuk minyak pelumas dan $0,87 \mathrm{~g} \cdot \mathrm{g}^{-1}$ untuk minyak jelantah [8].

Menurut salah satu produk Enterch mengatakan bahwa cellusorb yang terbuat dari $100 \%$ selulosa dapat menjerap minyak di dalam air. Cellusorb ini sangat cocok digunakan untuk semua jenis hidrokarbon. Adsorben ini dapat menjerap minyak di dalam air hingga 19 kali bobotnya [5]. Dalam penelitian ini cellusorb yang digunakan adalah pelepah pisang. Pelepah pisang memiliki kandungan selulosa $63 \%$ dan 
pemanfaatannya dari pelepah pisang ini belum maksimal [11].

Atas dasar inilah, peneliti ingin memanfaatkan limbah lateks karet alam yang telah overcured dan menggunakan bubuk pelepah pisang sebagai pengisi. Diharapkan penambahan bubuk pelepah pisang ini dapat meningkatkan kemampuan daya adsorpsi limbah lateks karet alam untuk dijadikan adsorben minyak.

\section{Teori}

Tumpahan Minyak

Tumpahan minyak atau Oil spill adalah perilisan sebuah cairan minyak hidrokarbon ke dalam lingkungan akibat kegiatan manusia, dan merupakan bentuk polusi. Pembersihan dan pemulihan dari tumpahan minyak sangat sulit dan tergantung pada banyak faktor, termasuk jenis minyak yang tumpah, suhu air, dan jenis garis pantai dan pantai yang terlibat. Beberapa teknik penanggulangan tumpahan minyak diantaranya in-situ burning, penyisihan secara mekanis, bioremediasi, penggunaan sorbent, penggunaan bahan kimia dispersan, dan washing oil [1].

\section{Lateks Karet Alam}

Lateks karet alam merupakan suatu cairan berwarna putih sampai kekuningan yang diperoleh dengan cara penyadapan. Pada tumbuhan, lateks diproduksi oleh sel-sel yang membentuk suatu pembuluh tersendiri yang disebut pembuluh lateks. Lateks terdiri atas partikel karet dan bahan bukan karet (non-rubber) yang terdispersi di dalam air. Lateks juga merupakan suatu larutan koloid dengan partikel karet dan bukan karet yang tersuspensi di dalam suatu media yang mengandung berbagai macam zat [13].

Karet alam mengandung seratus persen cis-1,4poliisoprena, yang terdiri dari rantai polimer lurus dan panjang dengan gugus isoprenik yang berulang, seperti yang diilustrasikan oleh gambar 1 berikut [10].

$$
\left[\begin{array}{c}
\stackrel{\mathrm{CH}_{3}}{\mathrm{C}}=\mathrm{CH}-\mathrm{CH}_{2} \\
\mathrm{CH}_{2}-\mathrm{n}
\end{array}\right.
$$

\section{Gambar 1. Monomer dari cis-1,4-poliisoprena}

Sebelum lateks digunakan untuk menghasilkan produk perlu dilakukan sambung-silang terlebih dahulu. Tujuan penyambung-silangan lateks adalah untuk menentukan kekuatan film lateks yang dihasilkan agar mencapai spesifikasi yang diinginkan. Proses penyambung-silangan bagi lateks dilakukan dengan mencampurkan bahan tambahan tertentu kedalam lateks. Bahan tambahan didalam campuran lateks pada mulanya memiliki ukuran butiran yang lebih besar dari ukuran partikel lateks itu sendiri. Jadi bahan tambahan ini perlu disediakan dalam bentuk dispersi supaya dapat disebarkan dengan baik dalam partikel lateks. Berdasarkan fungsinya, maka bahan tambahan atau bahan pembantu proses dapat dikelompokkan menjadi : bahan pelunak (plasticizer), bahan penstabil (stabilizer), bahan pelumas (lubricant), bahan pengisi (filler), pewarna (colorant), dsb [12].

\section{Adsorben}

Adsorben merupakan zat padat yang dapat menyerap komponen tertentu dari suatu fase fluida. Kebanyakan adsorben adalah bahan- bahan yang sangat berpori dan adsorpsi berlangsung terutama pada dinding pori- pori atau pada letak-letak tertentu di dalam partikel itu. Oleh karena pori-pori biasanya sangat kecil maka luas permukaan dalam menjadi beberapa orde besaran lebih besar daripada permukaan luar dan bisa mencapai $2000 \mathrm{~m} / \mathrm{g}$. Pemisahan terjadi karena perbedaan bobot molekul atau karena perbedaan polaritas yang menyebabkan sebagian molekul melekat pada permukaan tersebut lebih erat daripada molekul lainnya. Adsorben yang digunakan secara komersial dapat dikelompokkan menjadi dua yaitu kelompok polar dan non polar [4].

\section{Adsorpsi}

Adsorpsi adalah suatu proses pemisahan dimana komponen dari suatu fase fluida berpindah ke permukaan zat padat yang menyerap (adsorben). Biasanya partikel-partikel kecil zat penyerap dilepaskan pada adsorpsi kimia yang merupakan ikatan kuat antara penjerap dan zat yang dijerap sehingga tidak mungkin terjadi proses yang bolakbalik[4]. Secara umum, faktor-faktor yang mempengaruhi proses adsorpsi adalah sebagai berikut:

1. Agitation (Pengadukan) Tingkat adsorbsi dikontrol baik oleh difusi film maupun difusi pori, tergantung pada tingkat pengadukan pada sistem.

2. Karakteristik Adsorban (Karbon Aktif) Ukuran partikel dan luas permukaan merupakan karakteristik penting karbon aktif sesuai dengan fungsinya sebagai adsorban. Ukuran partikel karbon mempengaruhi tingkat adsorbsi; tingkat adsorbsi naik dengan adanya penurunan ukuran partikel. Oleh karena itu adsorbsi menggunakan karbon PAC (Powdered Acivated Carbon) lebih cepat dibandingkan dengan menggunakan karbon GAC (Granular Acivated Carbon). Kapasitas total adsorbsi karbon tergantung pada luas permukaannya. Ukuran partikel karbon tidak mempengaruhi luas permukaanya. Oleh sebab itu GAC atau PAC dengan berat yang sama memiliki kapasitas adsorbsi yang sama.

3. Kelarutan Adsorbat Senyawa terlarut memiliki gaya tarik-menarik yang kuat terhadap pelarutnya sehingga lebih sulit diadsorbsi dibandingkan senyawa tidak larut.

4. Ukuran Molekul Adsorbat tingkat adsorbsi pada alifatik, aldehid, atau alkohol biasanya naik diikuti dengan kenaikan ukuran molekul. Hal ini dapat dijelaskan dengan kenyataan bahwa gaya 
tarik antara karbon dan molekul akan semakin besar ketika ukuran molekul semakin mendekati ukuran pori karbon. Tingkat adsorbsi tertinggi terjadi jika pori karbon cukup besar untuk dilewati oleh molekul.

5. $p H$ Asam organik lebih mudah teradsorbsi pada $p H$ rendah, sedangkan adsorbsi basa organik efektif pada $\mathrm{pH}$ tinggi.

6. Temperatur tingkat adsorbsi naik diikuti dengan kenaikan temperatur dan turun diikuti dengan penurunan temperatur [4].

Pada adsorpsi kimia, molekul-molekul yang teradsorpsi pada permukaan adsorben bereaksi secara kimia. Hal ini disebabkan pada adsorpsi kimia terjadi pemutusan dan pembentukan ikatan. Ikatan antara adsorben dengan adsorbat dapat cukup kuat sehingga spesies aslinya tidak dapat ditemukan kembali. Adsorpsi ini bersifat irreversibel dan diperlukan energi yang banyak untuk melepaskan kembali adsorbat (dalam proses adsorpsi). Pada umumnya, dalam adsorpsi kimia jumlah (kapasitas) adsorpsi bertambah besar dengan naiknya temperatur. Zat yang teradsorpsi membentuk satu lapisan monomolekuler dan relatif lambat tercapai kesetimbangan karena dalam adsorpsi kimia melibatkan energi aktivasi. Secara kualitatif perilaku adsorpsi dapat juga dipandang dari sifat polar ataupun nonpolar antara zat padat (adsorben) dengan komponen larutan (adsorbat). Adsorben polar akan cenderung mengadsorpsi kuat adsorbat polar dan lemah terhadap adsorbat nonpolar, demikian juga sebaliknya. Adsorben polar akan mengadsorpsi kuat zat terlarut polar dari pelarut nonpolar karena kelarutannya yang rendah dan mengadsorpsi yang lemah dari pelarut polar karena kelarutannya yang tinggi, demikian juga sebaliknya [10].

\section{Isoterm Adsorpsi}

Isoterm adsorpsi adalah hubungan yang menunjukkan distribusi adsorben antara fasa teradsorpsi pada permukaan adsorben dengan fasa cairansaat kesetimbangan pada temperatur tertentu. Pada penelitian ini digunakan persamaan isoterm Freundlich dan isoterm Langmuir. Adapun data kuantitatif yang didapat dari penelitan berupa daya jerap minyak per gram adsorben (q) dan konsentrasi minyak akhir pada air (c) selama waktu kontak maksimum ditentukan dengan persamaan isotherm adsorpsi Freundlich dan persamaan isotherm adsorpsi Langmuir untuk mengetahui karakteristik adsorpsi minyak oleh adsorben sedangkan daya adsorpsi maksimum dari adsorben dengan membuat kurva berdasarkan karakteristik yang diperoleh.

\section{Persamaan Isotherm Freundlich:}

$$
\mathrm{q}=\mathrm{K}_{\mathrm{f}} \cdot \mathrm{c}^{\mathrm{n}} \text { atau } \log \mathrm{q}=\log \mathrm{K}_{\mathrm{f}}+\mathrm{n} \cdot \log \mathrm{c}
$$

dimana: $\mathrm{q}=$ daya jerap ( $\mathrm{g}$ adsorbat/ $\mathrm{g}$ adsorben) $\mathrm{c}=$ konsentrasi adsorbat dalam fluida (air) ( $\mathrm{g}$ adsorbat/ $\mathrm{dm}^{3}$ fluida)

$\mathrm{n}$ dan $\mathrm{K}$ ( $\mathrm{dm}^{3}$ fluida/ $\mathrm{g}$ adsorben) adalah

konstanta dan didapat dari percobaan

Persamaan Isotherm Langmuir:

$$
\mathrm{q}=\frac{\mathrm{q}_{\mathrm{o}} \cdot \mathrm{c}}{\mathrm{K}+\mathrm{c}} \quad \text { atau } \quad \frac{\mathrm{c}}{\mathrm{q}}=\frac{\mathrm{K}}{\mathrm{qo}}+\frac{1}{\mathrm{qo}} \cdot \mathrm{c}
$$

dimana: qo = daya jerap maksimum (g adsorbat $/ g$ adsorben)

$\mathrm{q}=$ daya jerap ( $\mathrm{g}$ adsorbat $/ \mathrm{g}$ adsorben)

$\mathrm{c}=$ konsentrasi adsorbat dalam fluida (air) $(\mathrm{g}$ adsorbat/ $\mathrm{dm}^{3}$ fluida)

$\mathrm{K}$ (g adsorbat/ $\mathrm{dm}^{3}$ fluida) adalah konstanta dan didapat dari percobaan [9].

\section{Metodologi Penelitian}

Pembuatan Adsorben Minyak dari Limbah Lateks dan Pengisi Bubuk Pelepah Pisang

Pada penelitian ini, adsorben dibuat dengan menggunakan limbah lateks yang telah overcured, kemudian diisi dengan bubuk pelepah pisang 10 dan $20 \%(\mathrm{~g} / \mathrm{g})$ kemudian dikeringkan dalam oven pada suhu $110{ }^{\circ} \mathrm{C}$ selama 5 jam. Setelah kering, limbah lateks dengan pengisi bubuk pelepah pisang diperkecil hingga diameter 1-3 mm. Adsorben disimpan dalam wadah tertutup.

\section{Analisa Daya Adsorpsi Minyak oleh Adsorben Minyak}

Sebanyak 2 g adsorben dimasukkkan ke dalam beaker glass yang berisi $100 \mathrm{ml}$ minyak pelumas. Adsorpsi dihentikan dengan variasi waktu 15, 30,45, 60,75, 90, 105 dan 120 menit. Adsorben disaring dan dicatat berat akhirnya, kemudian dicari daya adsorpsi tiap variasi waktu.

Daya adsorpsi dapat dicari dengan rumus :

$$
q=\frac{W-W_{o}}{W_{o}}
$$

dimana $: \mathrm{q}$ = Daya adsorpsi ( $\mathrm{g}$ minyak/ $\mathrm{g}$ adsorben)

$\mathrm{W}_{\mathrm{o}}=$ Berat adsorben mula - mula $(\mathrm{g})$

$\mathrm{W}=$ Berat adsorben akhir $(\mathrm{g})$

Penentuan Waktu Optimal Adsorpsi Minyak Pelumas dalam Air oleh Adsorben Limbah Lateks dengan Pengisi Bubuk Pelepah Pisang

Sebanyak 6 g minyak pelumas dimasukkan dalam beaker glass berisi $100 \mathrm{ml}$ air. Kemudian dimasukkan 4 $\mathrm{g}$ adsorben minyak dan diaduk dengan magnetic stirrer dengan kecepatan $170 \mathrm{rpm}$. Agitasi dihentikan pada waktu 2, 5, 15, 30 dan 60 menit. Adsorben disaring dan dicatat berat akhirnya. Filtrat minyak-air dianalisa kadar minyaknya dengan heksana (US EPA Method 10056). Kemudian dihitung daya adsorpsi adsorben dengan rumus berikut: 


$$
q=\frac{\left(c_{o}-c\right) V}{W}
$$

dimana $: \mathrm{q}=$ Daya adsorpsi ( $\mathrm{g}$ minyak/ $\mathrm{g}$ adsorben $)$

$\mathrm{W}=$ Berat adsorben $(\mathrm{g})$

$\mathrm{c}_{\mathrm{o}}=$ Konsentrasi awal minyak pelumas dalam air (g minyak/ L larutan)

$\mathrm{c}=$ Konsentrasi akhir minyak pelumas dalam air (g minyak/ L larutan)

$\mathrm{V}=$ Volume Larutan (ml)

Analisa Karakteristik Adsorpsi Minyak Pelumas dalam Air dengan Adsorben Minyak

Sebanyak $4 \mathrm{~g}$ adsorben dimasukkan ke dalam beaker glass yang berisi $100 \mathrm{ml}$ air dengan variasi berat minyak 2, 4, 6, 8 dan 10 g. Diaduk dengan magnetic stirrer dengan kecepatan $170 \mathrm{rpm}$. Pengadukan dihentikan pada waktu kontak optimal. Adsorben disaring dan dicatat berat akhirnya. Filtrat minyak-air dianalisa kadar minyaknya dengan heksana (US EPA Method 10056). Kemudian dihitung daya adsorpsi adsorben dengan persamaan (4).

\section{Hasil}

Analisa Daya Adsorpsi Minyak oleh Adsorben Minyak

Pada penelitian ini, $2 \mathrm{~g}$ adsorben minyak digunakan untuk mengadsorpsi minyak dalam waktu $15-120$ menit dan dihitung daya adsorpsi minyak pelumas dengan selang waktu 15 menit. Kurva hubungan daya adsorpsi minyak oleh adsorben yang berpengisi bubuk pelepah pisang 10\% (Adsorben A) dan 20\% (Adsorben B) terhadap waktu kontak disajikan pada Gambar 2.

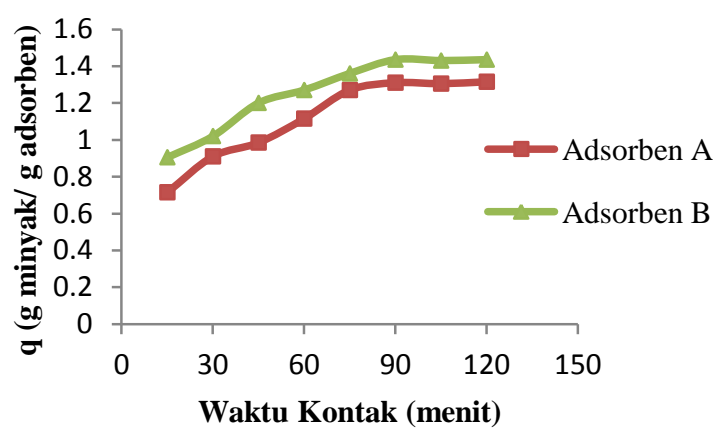

Gambar 2. Kurva Hubungan Daya Adsorpsi Minyak Pelumas oleh Adsorben Minyak terhadap Waktu $\operatorname{Kontak}\left(T=30^{\circ} \mathrm{C} ; 2\right.$ gram adsorben; tanpa pengadukan $)$

Pada Gambar 2 dapat dilihat daya adsorpsi minyak oleh adsorben minyak terus meningkat dengan bertambahnya waktu kontak. Hal ini disebabkan karena sifat oleofilik dari adsorben sehingga daya adorpsi semakin meningkat. Daya adsorpsi minyak oleh adsorben minyak mulai konstan pada menit ke-90,dan didapat daya adsorpsi minyak maksimum pada menit ke-105 sebesar 1,305 g minyak/ g adsorben untuk adsorben A dan 1,43 g minyak/ $\mathrm{g}$ adsorben untuk adsorben B. Dari grafik juga dapat dilihat bahwa semakin besar jumlah pengisi bubuk pelepah pisang maka daya adsorpsi adsorben semakin meningkat. Hal ini disebabkan kandungan selulosa pada bubuk pelepah pisang bersifat oleofilik [4].

Penentuan waktu Optimal Adsorpsi Minyak Pelumas dalam Air oleh Adsorben Minyak

Sebanyak 4 gram adsorben minyak digunakan untuk mengadsorpsi $6 \mathrm{~g}$ minyak pelumas dari $100 \mathrm{ml}$ air $(56,2343 \mathrm{~g} / \mathrm{L})$ dengan konsentrasi selama waktu tertentu dengan pengadukan $170 \mathrm{rpm}$. Kurva hubungan daya adsorpsi minyak oleh adsorben yang berpengisi bubuk pelepah pisang 10\% (Adsorben A) dan 20\% (Adsorben B) terhadap waktu kontak disajikan pada Gambar 3.

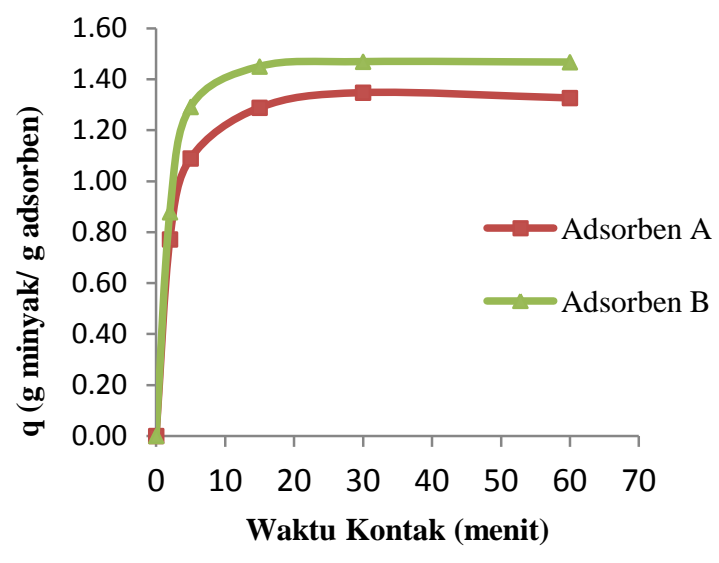

Gambar 3. Kurva Hubungan Daya Adsorpsi Minyak Pelumas dalam Air oleh Adsorben Minyak terhadap Waktu

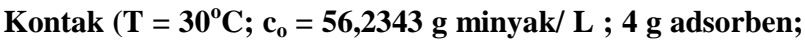
170 rpm)

Pada adsorpsi minyak pelumas dalam air ini, diinginkan adsorben minyak harus memiliki sifat oleofilik dan hidrofobik sehingga bisa menjerap minyak dari air [6].

Dari Gambar 3 dapat dilihat daya adsorpsi minyak pelumas dalam air oleh adsorben berlangsung cepat pada awal adsorpsi, kemudian mulai konstan pada menit ke-15 dan daya adsorpsi maksimum minyak pelumas dari air oleh adsorben minyak terjadi pada menit ke-30. Hal ini terjadi karena adsorpsi minyak pelumas dari air oleh adsorben minyak merupakan peristiwa kesetimbangan. Waktu optimal adsorpsi minyak pelumas dalam air oleh adsorben minyak adalah 30 menit. 
Analisa Karakteristik Adsorpsi Minyak Pelumas dalam Air dengan Adsorben Minyak

Untuk mengetahui karakteristik adsorpsi minyak oleh adsorben dilakukan dengan mengamati jerapannya terhadap minyak dari air pada konsentrasi yang bervariasi dari 19,5633 g/L sampai 89,9598 g/L dan pada suhu isoterm sekitar $30{ }^{\circ} \mathrm{C}$. Dari hasil penjerapan tersebut selanjutnya dianalisis menggunakan persamaan isoterm adsorpsi Freundlich dan isoterm adsorpsi Langmuir untuk mengetahui karakteristik adsorpsi dan juga daya adsorpsi maksimumnya. Berikut adalah kurva linearitas Freundlich dan Langmuir pada Gambar 5, 6, 7 dan 8.

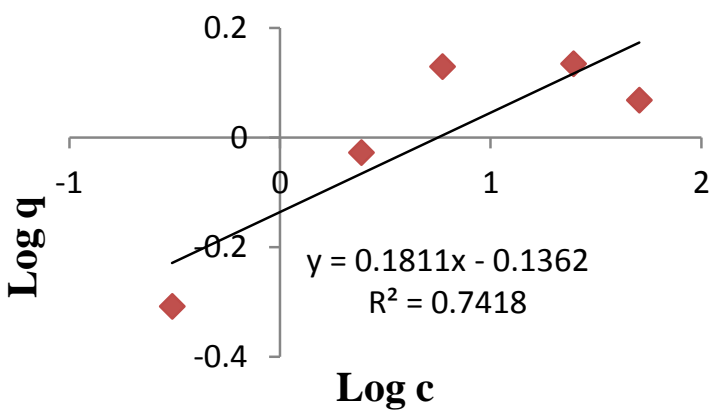

Gambar 4. Kurva Linearitas Freundlich: Hubungan antara Log c terhadap Log q pada Adsorpsi Minyak Pelumas dalam Air oleh Adsorben Minyak A $\left(\mathrm{T}=30^{\circ} \mathrm{C} ; 4\right.$ g adsorben; 170 rpm)

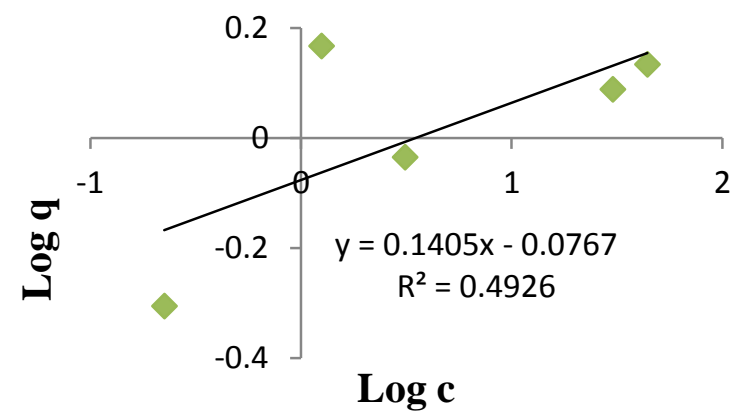

Gambar 5. Kurva Linearitas Freundlich: Hubungan antara Log c terhadap Log q pada Adsorpsi Minyak Pelumas dalam Air oleh Adsorben Minyak B $\left(\mathrm{T}=30^{\circ} \mathrm{C} ; 4\right.$ g adsorben; 170 rpm)

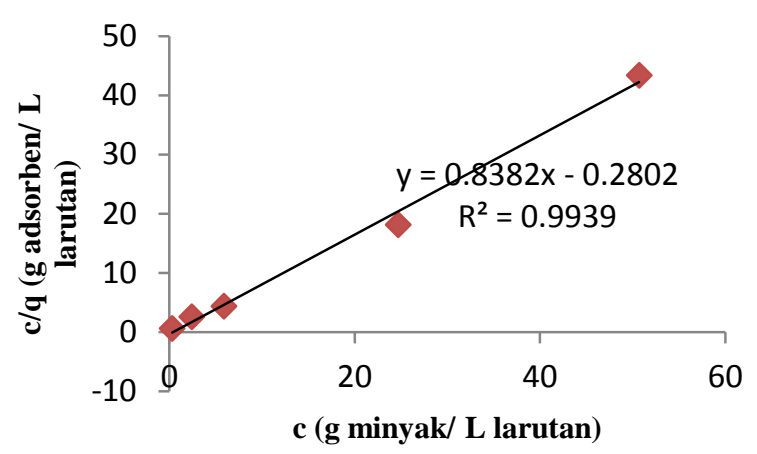

Gambar 6. Kurva Linearitas Langmuir: Hubungan Antara c terhadap c/q pada Adsorpsi MinyakPelumas dalam Air oleh Adsorben Minyak $A\left(T=30^{\circ} \mathrm{C} ; 4 \mathrm{~g}\right.$ adsorben; 170 rpm)

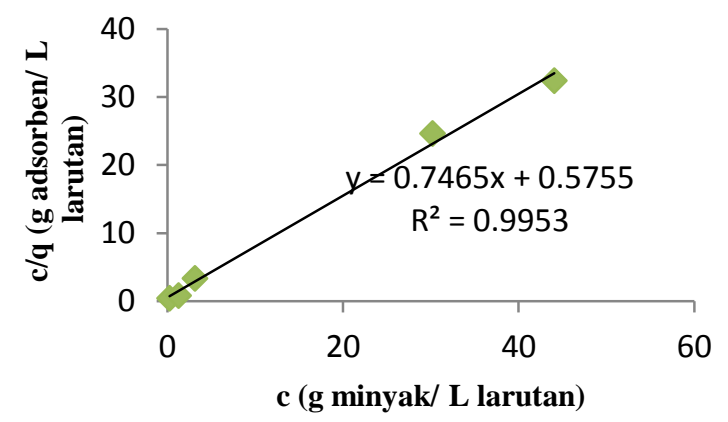

Gambar 7. Kurva Linearitas Langmuir: Hubungan Antara c terhadap c/q pada Adsorpsi Minyak Pelumas dari Air oleh Adsorben Minyak $B\left(T=30^{\circ} \mathrm{C} ; 4 \mathrm{~g}\right.$ adsorben; 170 rpm)

Berdasarkan nilai $\mathrm{R}^{2}$, persamaan isoterm Langmuir lebih cocok untuk adsorpsi minyak pelumas dari air oleh adsorben minyak. Nilai $\mathrm{R}^{2}$ untuk isoterm Langmuir sebesar 0,99 untuk adsorben A dan 0,995 untuk adsorben B sedangkan untuk isoterm Freundlich adalah 0,741 untuk adsorben A dan 0,492 untuk adsorben B. Ini disebabkan minyak yang digunakan adalah minyak pelumas yang terdiri dari senyawasenyawa yang berantai panjang dan mempunyai berat molekul yang besar. Sehingga adsorpsi minyak dari air oleh adsorben yang mengikuti persamaan isoterm Langmuir yang mana adsorbat hanya teradsorpsi secara unimolekular ke permukaan adsorben.

Kurva isoterm adsorpsi Langmuir, selanjutnya dapat dipakai untuk menentukan daya adsorpsi maksimum $\left(\mathrm{q}_{\mathrm{o}}\right)$ yaitu berdasarkan nilai dari slope (kemiringan garis) pada persamaan $\mathrm{Y}=0,906 \mathrm{X}+$ 0,855 , yaitu $1 / \mathrm{q}_{\mathrm{o}}$. Dengan mensubstitusi $1 / \mathrm{q}_{\mathrm{o}}=0,906$ maka diperoleh nilai $\mathrm{q}_{\mathrm{o}}=1,1038 \mathrm{~g}$ minyak/ $\mathrm{g}$ adsorben. Kemampuan adsorpsi maksimum minyak dari air oleh adsorben minyak diperoleh sebesar 1,1038 g minyak/ $\mathrm{g}$ adsorben. 


\section{Kesimpulan}

Adapun kesimpulan dari penelitian ini adalah penambahan bubuk pelepah pisang dapat meningkatkan kemampuan adsorpsi adsorben minyak dari limbah lateks dengan pengisi bubuk pelepah pisang. Pada penelitian ini diperoleh kemampuan daya adsorpsi adsorben dalam minyak pelumas dari limbah lateks dengan pengisi bubuk pelepah pisang sebesar $1,305 \mathrm{~g} \cdot \mathrm{g}^{-1}$ untuk adsorben dengan pengisi bubuk pelepah pisang $10 \%$ dan $1,43 \mathrm{~g} \cdot \mathrm{g}^{-1}$ untuk pengisi bubuk pelepah pisang $20 \%$. Untuk minyak pelumas dalam air diperoleh kemampuan adsorpsi adsorben sebesar $1,1933 \mathrm{~g} \cdot \mathrm{g}^{-1}$ untuk adsorben dengan pengisi bubuk pelepah pisang $10 \%$ dan $1,3405 \mathrm{~g}^{-1} \mathrm{~g}^{-1}$ untuk adsorben dengan pengisi bubuk pelepah pisang $20 \%$. Analisa karakteristik adsorpsi minyak pelumas oleh adsorben ini lebih menyerupai persamaan isoterm Langmuir karena bersifat unimolekular. Sehingga limbah lateks dengan pengisi bubuk pelepah pisang dapat dimanfaatkan menjadi adsorben minyak dengan kemampuan adsorpsi minyak yang cukup besar.

\section{Daftar Pustaka}

[1] Afif, Resume dan Analisa Terjadinya Oil Spill. http:// gatotkacablog.com, 2010.

[2] Aronu, U. E, "Absorption Mats for Oil Decontamination". Master of Science Thesis, Univ. College of Borås, Sweden, 2007.

[3] Baharin., Yan P. Meng, Marzio Ahmad, Yusof Mohd dan Arif. N. Zainal, Addition of over cured latex to compounded uncompounded and prevulcanised HA latex. Natural Rubber Curing Development In Product Manufacture and Applications : A report of proceeding of the International Rubber Technology Conference. RRIM, 1993.

[4] Carolina Panggabean, Proses Adsorpsi, 2012.

[5] Enretech, cellusorb NR025, 2012.

[6] Geankoplis, Christie J. Transport Processes and Separation Process Principles, Fourth Edition. Prentice Hall, 2003

[7] Ismai. H, OilZob: A Novel and Reactive Oil Adsorbent from Various Rubber Wastes. Universitas Sains Malaysia, 2005.

[8] Kania. D, Soewondo, Prayatni dan Valdes, Julio R. Pemisahan Minyak Pelumas Dan Minyak Jelantah Dari Air Melalui Absorpsi Pada Partikel Karet Ban ITB, 2010.

[9] Mc Cabe, Warren L. Unit Operation of Chemical Engineering, Mc Graw-Hill Book Inc, 1999.

[10] Morton, M. Rubber Technology, Third Edition. Van Nostard Reinhold. New York, 1987

[11] Noviati, Rizka, Perbandingan Daya Absorbsi Ion $\mathrm{Cr}^{3+}$ Pada Serbuk Gergaji Kayu Albizia Dengan Zeolit Ditinjau Dari Teori HSAB. FMIPA. Universitas Brawijaya, Malang, 2011.
[12] Surya. I, Buku Ajar Teknologi Karet, Universitas Sumatera Utara, Medan, 2006.

[13] Triwijoso, Sri Utami. Pengetahuan Umum Tentang Karet Hevea. Dalam Kumpulan Makalah: In House Training, Pengolahan Lateks Pekat dan Karet Mentah. No : 1. Balai Penelitian Teknologi Karet Bogor, Bogor, 1995. 